\title{
Fear Network Model in Panic Disorder: The Past and the Future
}

\author{
Chien-Han Lai ${ }^{1,2,3} \bowtie$ \\ ${ }^{1}$ Institute of Biophotonics, National Yang-Ming University, Taipei, Taiwan \\ ${ }^{2} \mathrm{PhD}$ Psychiatry \& Neuroscience Clinic, Taoyuan, Taiwan \\ ${ }^{3}$ Department of Psychiatry, Yeezen General Hospital, Taoyuan, Taiwan
}

\begin{abstract}
The core concept for pathophysiology in panic disorder (PD) is the fear network model (FNM). The alterations in FNM might be linked with disturbances in the autonomic nervous system (ANS), which is a common phenomenon in PD. The traditional FNM included the frontal and limbic regions, which were dysregulated in the feedback mechanism for cognitive control of frontal lobe over the primitive response of limbic system. The exaggerated responses of limbic system are also associated with dysregulation in the neurotransmitter system. The neuroimaging studies also corresponded to FNM concept. However, more extended areas of FNM have been discovered in recent imaging studies, such as sensory regions of occipital, parietal cortex and temporal cortex and insula. The insula might integrate the filtered sensory information via thalamus from the visuospatial and other sensory modalities related to occipital, parietal and temporal lobes. In this review article, the traditional and advanced FNM would be discussed. I would also focus on the current evidences of insula, temporal, parietal and occipital lobes in the pathophysiology. In addition, the white matter and functional connectome studies would be reviewed to support the concept of advanced FNM. An emerging dysregulation model of fronto-limbic-insula and temporo-occipitoparietal areas might be revealed according to the combined results of recent neuroimaging studies. The future delineation of advanced FNM model can be beneficial from more extensive and advanced studies focusing on the additional sensory regions of occipital, parietal and temporal cortex to confirm the role of advanced FNM in the pathophysiology of PD.

Psychiatry Investig 2019;16(1):16-26
\end{abstract}

Key Words Fear network model, Panic disorder, Fronto-limbic, Temporo-occipito-parietal cortex, Insula.

\section{INTRODUCTION}

The symptoms of panic disorder (PD) include recurrent panic attacks with the following example symptoms, such as fear of losing control, feel like dying, chest tightness, shortness of breathing, palpitations, dizziness, abdominal discomforts and other physical symptoms with unknown etiology. It is an important anxiety illness but usually under-recognized, ${ }^{1}$ which is associated with the impairments in life qualities and somatic feelings. ${ }^{2}$ PD is easily comorbid with other mental illnesses. ${ }^{3} \mathrm{PD}$ is also related to diminished well-being, poor sense of health, decline in qualities of life, frequent utilization of medical services, occupational impairments, financial dependency, and marital strife due to recurrent panic attacks and

Received: March 24, 2018 Revised: April 23, 2018

Accepted: May 4, 2018

$\triangle$ Correspondence: Chien-Han Lai, MD, PhD

Institute of Biophotonics, National Yang-Ming University, No.155, Sec.2, Linong Street, Taipei, 112 Taiwan (ROC)

Tel: +886-2-2826-7000, Fax: +886-2-2823-5460, E-mail: stephenlai99@gmail.com

(a) This is an Open Access article distributed under the terms of the Creative Commons Attribution Non-Commercial License (https://creativecommons.org/licenses/by$\mathrm{nc} / 4.0$ ) which permits unrestricted non-commercial use, distribution, and reproduction in any medium, provided the original work is properly cited. anticipatory anxiety. ${ }^{2,45}$ The traditional pathophysiology of PD was originated from Gorman's hypothesis of "fear network model (FNM)". The FNM included frontal and limbic areas, such as insula, thalamus, periacqueductal gray matter, locus cerulus, parabrachial nucleus and nucleus of solitary tract, medial frontal gyrus, anterior cingulate, amygdala and hippocampus, brainstem, hypothalamus. The frontal areas should modulate the exaggerated fear reactions of the limbic regions properly. Inadequate control of fear response will provoke panic attacks. ${ }^{6}$ The subliminal fear is processed via cortical-cortical and cortico-subcortical functional connection. ${ }^{7}$ The fear and arousal of panic symptoms are related to attention modulation toward threat band emotional salience of the threat. ${ }^{8}$ The center of traditional FNM is the amygdala, which is connected with medial frontal cortex and hippocampus for the control of fear response and fear memory. In addition, the projections from amygdala are linked with brainstem and hypothalamus for the panic symptoms related to the dysfunction of autonomic nervous system. The dysfunction of FNM is usually associated with early childhood life stressors and genetic loading. The serotonin-related medications, such as antidepressants, can relieve the panic symptoms 
via the decrease in the exaggerated fear response between amygdala and brainstem or hypothalamus. In addition, psychosocial interventions can enhance frontal cortex inhibitory ability for the amygdala and hippocampus. ${ }^{6}$ The hippocampus hyperexcitability would enhance the fear memories and the inhibitory neurotransmitter can help the suppression and extinction of fear response related to fear memory. ${ }^{9}$ The traditional FNM is associated with the dysregulation of cholecystokinin, serotonin, glutamate, norepinephrine, gamma-aminobutyric acid systems. ${ }^{10,11}$ However, recent neuroimaging studies revealed that no such distinct and specific pathways for the medication and psychosocial interventions as Gorman et al. mentioned in their original hypothesis. In addition, recently another review of panic disorder focused on the neuroimaging reports, such as functional, metabolic and structural imaging studies. The review mentioned the hyperactive amygdala should be a state biomarker, not a trait biomarker. The alterations in the cortico-limbic interaction were replicated with further involvements of extended areas, such as anterior cingulate cortex and insula. ${ }^{10,12}$ However, the interindividual differences of the FNM for each patient might be associated with inter-individual differences of panic symptoms and clinical responses to treatment. ${ }^{13}$ Further advanced FNM should include more potential extension areas. In my viewpoint, the sensory-related brain regions, such as temporal, occipital and parietal should be included in the advanced FNM for the pathophysiology of PD. Since most panic symptoms, such as chest tightness, shortness of breathing, dizziness, palpitations, paresthesia and abdominal pain, etc., are related to sensory function and response. Therefore, this review would reveal the importance of extended areas for the advanced FNM, especially for the sensory regions. I will also review whether the functional connectivity of traditional FNM is associated with sensory-related brain regions and whether the connectivity of sensory-related brain regions will be modulated through thalamus and insula in the following sections.

\section{EXTENDED AREAS OF FNM}

\section{The advanced FNM evidences for temporal regions}

The model of fear circuitry in PD consists of lateral nucleus of amygdala, hippocampus, frontal cortex, insula, thalamus, anterior cingulate, hypothalamus and brainstem, which are interacted with each other to modulate the panic responses. ${ }^{6,14,15}$ For the gray matter (GM), the voxel-based morphometry (VBM) analysis showed an extended region, temporal lobe, which was not included in the traditional FNM. ${ }^{16-22}$ Several VBM studies reported alterations in the temporal regions, even with opposite findings of GM volumes, such as decreased $\mathrm{GM}^{17,23}$ and increased GM in PD patients. ${ }^{22}$ The alterations of temporal lobe might be associated with the inhibitory function of frontal cortex. The alterations in the frontal regions of PD patients have been mentioned in several VBM reports ${ }^{17,20,21,23-26}$ and the GM volumes were negatively correlated with the severity of PD symptoms. ${ }^{23}$ The frontal regions might use "top-down mechanism" to process the sensory messages from temporal regions to control the subsequent panic attacks. ${ }^{27}$ In addition to the structural studies, there are some functional studies showing the crucial role of temporal lobe for the pathophysiology of panic disorder. Regional cerebral blood flow was decreased in the superior temporal gyrus and negatively correlated with the panic severity, anxiety level and illness duration. ${ }^{28}$ Nash et al. ${ }^{29}$ found decreased presynaptic and postsynaptic serotonin $1 \mathrm{~A}$ receptor bindings in the orbitofrontal cortex and temporal regions of PD patients. The stimulations of panicogenic will also induce panic attacks through decreased ability of inferior frontal cortex to control the panic responses. ${ }^{30}$

The sensory-related function has been discussed for the temporal lobe in PD, which included the visuospatial dysfunction and false threat alarm in patients with PD. ${ }^{14,22,31-34}$ The impairments in integrating sensory information through the visuospatial system and attention were also reported..$^{22}$ In addition, PD patients had deficits to suppress the interference of nonverbal stimuli and reduced verbal cognitive ability to express abstract thoughts. ${ }^{35}$ In the traditional FNM, the additional sensory-related structures, such as temporal lobes and parietal lobes, were not crucial areas. ${ }^{6}$ However, fear-related acute stressors would activate infero-temporal, temporo-parietal and limbic structures to exchange information between autonomic-neuroendocrine systems and re-orient vigilant attention. ${ }^{36}$ The fear conditioning would increase brain activities in the frontal, temporal and parietal lobes. ${ }^{37}$ Our antidepressant treatment study in $\mathrm{PD}$ also showed increased regional homogeneity of temporal lobe and decreased regional homogeneity of parietal lobe after remission of panic symptoms under antidepressant therapy. ${ }^{38}$ Fearful faces stimuli would also induce spatial attention and interact with emotion, which were associated with temporo-parietal negativity and the activities in occipital lobe. ${ }^{39}$ The external stressors and related panic attacks would increase brain activities in thalamus and occipito-temporo-parietal regions. ${ }^{40}$ The strong and robust activations in superior temporal lobe and several limbic structures would also occur during panic attacks. ${ }^{41}$ The increased cerebral activities of superior temporal lobe in $\mathrm{PD}$ patients also replicated the above studies. ${ }^{30}$ However, different points of view mentioned the opposite phenomenon, such as decreased regional cerebral blood flow in right superior temporal gyrus of PD patients. In addition, regional cerebral blood flows in right superior temporal gyrus were negatively 
correlated with the duration of illness, severity of clinical anxiety and PD symptoms. ${ }^{28}$ However, decreased regional cerebral blood flow in right superior temporal gyrus of PD patients has been reported in another study. In addition, regional cerebral blood flow in right superior temporal gyrus negatively correlated with the duration of illness, severity of clinical anxiety and PD symptoms. ${ }^{28}$ The functions of temporal lobe, such as the regulation of anxiety, ${ }^{42}$ selective aberrant functional connectivity ${ }^{43}$ regulation of mood status, ${ }^{42}$ the involvement of episodic memory and self-projection ${ }^{43}$ might be also impaired in PD. Several reports suggested that "fronto-temporoinsula" network might be altered in PD, which also included the temporal lobe. ${ }^{27,30,44}$ Antidepressant treatment would also be associated with the increased regional homogeneity (ReHo) of temporal lobe in the remitted patients with $\mathrm{PD}^{38}$ The activations in superior temporal gyrus have been observed during panic attacks, ${ }^{41}$ which also corresponded to hyperfusion of superior temporal gyrus in a positron emission tomography study. ${ }^{45}$

Several VBM studies of PD also supported the biomarker characteristics of temporal lobe, such as the GM alterations over this region. ${ }^{17,22,26}$ Increased GM volumes have been mentioned in superior temporal gyrus, which might be associated with the dense connection between insula and temporal lobe. ${ }^{22}$ However, decreased GM volumes have been observed in temporal lobe. ${ }^{23}$ Pure anxiety disorders also had deficits of GM volume in superior temporal gyrus, ${ }^{26}$ which might work with amygdala and insula to control the panic attacks. In addition, the alterations in the temporal lobe might influence the spread of sensory information to the thalamus for further filtering and subsequent "top-down" regulation of the frontal system. ${ }^{6}$ In addition, the fractional amplitude of low frequency fluctuations in the temporal lobe might be dissociated with those in the fronto-parietal lobe. ${ }^{46}$ These studies supported that the advanced FNM should include the temporal lobe.

\section{The advanced FNM evidences for insula}

Insula might integrate multimodal sensory information due to dense connections with other brain regions, such as frontal and temporal regions. The insula might modulate the panic responses via this fronto-temporo-insula network. ${ }^{27,44,47}$ The alterations of GM in insula have been mentioned in several VBM studies in PD. ${ }^{17,22,27,48}$ In the traditional FNM, the insula received the thalamus-filtered sensory information and cooperated with frontal regions to control panic attacks. ${ }^{6}$

The alterations of insula GM have been mentioned in several VBM studies with opposite findings, such as decreased GM volumes ${ }^{17,27,49}$ and increases in GM volume. ${ }^{22,48}$ The insula is also a crucial area for the somatic and cognitive pathophysiology of PD..$^{50,51}$ The inconsistent findings also occurred in the functional studies of PD patients, such as increased brain activity ${ }^{48}$ or decreased brain activity. ${ }^{30}$ The typical fear due to danger threat response also decreased the coupling between insula and frontal cortex. ${ }^{52}$ The visceral-somatic afferent and efferent impairments were also associated with decreased gamma amino-butyric acid binding in insula of PD patients. ${ }^{53}$ The fear of cardiovascular symptoms in PD, response of visual threat, anxiety sensitivity during emotional face processing, anticipating anxiety towards the agoraphobia situation, prediction of cognitive behavioral therapy, $\mathrm{pH}$ sensitivity functional imaging and unpredictable aversiveness for avoidance response were also associated with the activations of insu$1 a^{54-61}$ in an extended version of fear network. ${ }^{12,62}$ The anxiety sensitivity was negatively correlated with white matter (WM) microintegrity. ${ }^{63}$ From these literature, insula might play a crucial role for the processing of cognitive, emotional, fearful and primitive response during panic attacks. It should be included in the advanced FNM based on the numerous structural and functional imaging studies.

\section{The advanced FNM evidences for thalamus}

The thalamus regulates emotional and cognitive functions, such as fear, arousal, attention modulation towards threat, emotional perseveration of threat, state anxiety for threat monitoring, shock monitoring and sensory processing. ${ }^{8,15,64}$ The thalamus interacts with temporal, parietal, subcortical limbic structures, or other parts of fear network structures to modulate the noradrenergic system response towards fear. ${ }^{36,40,64}$ It is a part of fear network and can regulate fear response towards threat. ${ }^{6,65}$ In addition, our previous study about RFMRI also found alterations of fractional amplitude of low frequency fluctuations in thalamus. ${ }^{66}$ Pentazatos et al. ${ }^{67}$ reported that fearful face presentation would provoke functional connectivity between AG and hippocampus. In addition, thalamus will connect with temporal lobe and insula for the pathogenesis of PD.

\section{The advanced FNM evidences for parietal lobe}

Serotonin-related functional alterations have been found in the parieto-superior temporal regions of PD patients. ${ }^{68} \mathrm{An}$ other kind of anxiety disorder, social anxiety disorder, had alterations in the neural activities ${ }^{69}$ and diffuse impacts on wide resting-state network and selective changes of intrinsic functional connectivity of parietal lobe. ${ }^{43}$ The regional cerebral blood flow asymmetry index in temporal and parietal lobes was associated with panic severity. ${ }^{70}$ Anxiety-provoking situation also had the phenomenon of decreased cerebral blood flow in parietal lobe. ${ }^{71}$ The reductions in regional cerebral blood flows were also observed in the posterior parietal-superior temporal areas of PD patients. ${ }^{68}$ The anxiety severity was inversely correlated with the metabolisms in temporal and 
parietal regions in mood disorder. ${ }^{72}$

The GM volume of parietal lobe is associated with anxiety and mood, affective regulation, empathic response, meditation and clamness. ${ }^{42}$ Several VBM reports in PD showed reductions in GM volumes of parietal and temporal lobes. ${ }^{17,73}$ The decreased cortical thickness in the parietal lobe was also mentioned in PD. ${ }^{74}$ The cortical gyrification was also decreased in the parietal and temporal lobes. ${ }^{75}$

The parietal-related visuospatial dysfunction might be the component issue for the pathophysiology of $\mathrm{PD} .{ }^{76}$ The activities of parietal lobule and other advanced FNM regions might predict the treatment response to cognitive behavioral therapy ${ }^{77}$ which is replicated in another study. ${ }^{78}$ In addition, the antidepressant treatment in remitted patients with PD was associated with the changes of ReHo in the parietal lobe. ${ }^{38}$ The study between panic symptom and $\mathrm{pH}$ functional imaging study also showed the significant relationship with the parietal lobe, insula and temporal lobe. ${ }^{60} \mathrm{PD}$ patients also had decreased inter-hemispheric coordination between bilateral parietal lobes. ${ }^{79}$ The elevated activities of right parietal lobe occurred while anxious patients performed the task. ${ }^{80}$

The precuneus, a part of default mode network, has been reported to be altered in $\mathrm{PD},{ }^{66,81,82}$ which might have impairments of emotion, somatosensory and self-referential processing functions. ${ }^{83}$ In addition, the functional connectivity between anterior cingulate and precuneus was increased in PD, which was associated with the concentration of gamma-aminobutyric acid. ${ }^{84}$ An aberrant limbic network between amygdala and precuneus was also found in PD, which might have dysregulation of emotional and somatosensory processing. ${ }^{83}$ If the disturbances happened in this network, the emotional and somatosensory processing might be misleading and provoke panic attacks. The alterations in the functional connectivity between dorsal anterior cingulate cortex and precuneus might link anxiety with deficits in self-awareness. ${ }^{85}$ In addition, the precuneus-related functions included the attention monitoring, response inhibition, motivation-independent neural process, ${ }^{86}$ somatosensory processing, emotional processing, visual imagery recall and self-reflection process, ${ }^{87-89}$ which would be impaired in PD. The decreased parietal activation during avoidance response to affective stimuli was also observed in PD. ${ }^{90}$ From the above literature, the parietal lobe should be included in the advanced FNM due to its related sensory function and cognitive function, which corresponds to another review article. ${ }^{12}$

\section{The advanced FNM evidences for occipital lobe}

Sensory regions of brain, such as occipital or temporal lobe, will transmit the sensory information to FNM for recognizing and processing fear signals of face and body. ${ }^{91}$ The fear processing, sensory and inhibitory function might be associated with regional instability of the occipital lobe in PD. ${ }^{81}$ The anxious response, sensory-related fear, dysfunctions of self regulation might occur in the occipital lobe of anxiety patients. ${ }^{92}$ The anticipatory anxiety, a crucial trait of $\mathrm{PD}$, might increase while higher level of neuroticism. Anticipatory fear was believed to be induced by abnormal brain activities of occipital lobe. ${ }^{93}$ In addition, the occipital lobe was associated with face recognition, sensitivity to fearful stimuli, emotion processing and levels of trait anxiety. ${ }^{94,95}$ The worry also seemed to decrease regional blood flow in occipital lobe, which confirmed the role of occipital lobe in the worry model for PD. ${ }^{96}$ The occipital lobe was related to sensory processing of auditory-spatial and visuospatial information. ${ }^{97,98}$ The environmental changes, such as visual or sensory changes, would elicit the responses in the middle occipital gyrus. Sensory changes might precipitate panic attacks, which might suggest that occipital lobe should be a part of FNM. ${ }^{99}$

$\mathrm{PD}$ is associated disturbances of sensory processing and integration. ${ }^{100}$ The limbic system might receive abnormal sensory signals from occipital lobe, which would provoke panic symptoms in the brainstem. The dorsal attention system, which includes the middle occipital gyrus, controls top-down procedure for selective attention and sensory modulation. ${ }^{43}$ The connectivity between occipital lobe and other regions would be impaired due to excessive anxiety and fear. ${ }^{101,102} \mathrm{PD}$ patients had abnormal activities in occipital lobes, basal ganglion and thalamus while receiving negative emotion stimulus. ${ }^{103}$ In addition, the 5 HT-1A receptor binding potential of occipital lobe was negatively correlated with anxiety levels. ${ }^{104}$

In addition to middle occipital gyrus, the visual association cortex (a part of occipital lobe) might be another important part of the FNM. The attention, perception, visual identification, recognition memory, visuospatial ability and interoceptive sensory information processing ${ }^{105-107}$ of visual association cortex might be impaired in PD. ${ }^{22}$ The shock-related fear might impair the memory consolidation in bilateral lingual gyrus, ${ }^{108}$ which was associated with significant rapid eye movement sleep and impaired consolidation of fear extinction. ${ }^{108}$ The link between amygdala and visual association cortex was responsible for processing fearful faces and spatialrelated information. ${ }^{109}$ The results were also in line with altered spatial-related attention due to impaired connection between amygdala and visual area in PD. ${ }^{109}$ Visual association cortex was also associated with the regulation of visual imagery and autonomic function, ${ }^{110}$ sympathetic activity and the processing of autonomic function, ${ }^{111,112}$ the perceptions of bodily expressions, threatening of fear signals, ${ }^{113}$ and anticipatory anxiety, ${ }^{93}$ which might be impaired in PD. The fear, perception arousal, autonomic dysregulations, and anticipatory anxiety 
are core symptoms and presentations of PD. Therefore, visual association cortex might be a component of FNM of PD.

We ever reported significant GM deficits in occipital lobe of PD patients who were comorbid with major depressive disorder. ${ }^{20}$ Our another report of ReHo in PD also showed alterations in occipital lobe might be a part of FNM ${ }^{81}$ In addition, the impaired fractional amplitude of low frequency fluctuations have been observed in the middle occipital gyrus of PD patients. ${ }^{66}$ The lingual gyrus was connected with amygdala to form the FNM for the spatial attention ability and fear-processing in PD. ${ }^{109}$ In the advanced FNM, occipital lobe might work with medial structures (such as thalamus and amygdala), frontal regions and other sensory region (such as superior temporal lobe) to process the fear identification and adaptation. ${ }^{114}$ The occipital lobe probably send the sensory information through the sensory afferents to the thalamus, amygdala and hippocampus, which are core structures of fear circuitry of PD.

The hyperoxic ventilation challenge elevated the activities in occipital lobe. The addition of carbon dioxide abolished the abnormal response of occipital lobe. ${ }^{115}$ In addition, panic attacks from the stress of social interaction might be associated with alterations in the occipital lobe for neural processing of social cognition, social rejection sensitivity and low confidence fear. ${ }^{116,117}$ The lingual gyrus also regulates the anxiety, vigilance and cardiovascular functions. ${ }^{118}$ The visual processing, orientation-specific function of occipital lobe, ${ }^{119}$ the visuospatial ability, somatosensory stimulation and perception of sensory stimulus ${ }^{120}$ suggested that the impairments in sensory integration might predispose to panic attacks. In addition, antidepressant treatment enhanced the brain activities in occipital lobe and relieved the panic attacks. ${ }^{121}$

The cuneus, another part of visual association cortex, might also connect with core structures of FNM via sending sensory information to the amygdala, hippocampus and thalamus. The bottom-up control of visuospatial selective attention, which was called stimulus-driven attention, also occurred in the cuneus. ${ }^{122}$ The occipital lobe seemed to be interconnected with default mode network and limbic regions for the control of vigilance, attention, motivationand arousal. ${ }^{123}$ The occipital lobe was also linked with four cortical networks, such as default mode network, dorsal attention, visual and somatosensory network. ${ }^{124}$ The cholecystokinin-4 related model of panic attacks found that brain activations of cuneus were associated with fear scores through the connection with amygdala. ${ }^{41}$ Abused women showed abnormal activities of right cuneus and right visual processing regions during response inhibition task. ${ }^{125}$ As we know, PD is also usually related to childhood abuse ${ }^{126}$ and cuneus might be a crucial part of advanced FNM. In addition, cuneus was responsible for visuo- spatial attention of threat, ${ }^{127}$ voice identifications, faces processing and proneness to anxiety reactions. ${ }^{128,129}$ In addition, the connectome study of PD showed decreased edge strength of functional connectivity from the right lingual gyrus. ${ }^{130}$ The residual alterations in the fractional amplitude of low frequency fluctuations might also occur in the occipital lobe even after antidepressant therapy with remitted status. ${ }^{131}$ The occipital lobe-related fasciculus was also altered in the active phase and remitted status of PD patients. ${ }^{132-134}$ The inappropriapte attention and sensitivity to the sensory stimulus, such as chest tightness and heart fast beating, might bring the panic attacks. The orienting-avoidance function of cuneus towards threatening events in anxious subjects might be related to avoidance behaviors of panic attacks. The incorrect somatic messages from occipital lobe might provoke the abnormal responses from core structures and send the abnormal responses to the brainstem and other regions to cause the panic attacks. Therefore the occipital lobe should be enrolled as a crucial component of advanced FNM.

\section{Supporting evidences from white matter study}

The current WM study focused on the microintegrity of fasciculus. The sensory-related WM fasciculus, such as fronto-occipital fasciculus (FOF) and uncinate fasciculus (UF), have been mentioned in the studies of anxiety. The FOF is a WM tract interacting with language-related WM fasciculus to connect the occipital lobe and frontal system through the parietal lobe. ${ }^{135}$ The frontal lobe is also the component of traditional FNM. ${ }^{6}$ The frontal lobe can control amygdala-related fear response, which is related to UF's connection between frontal lobe and amygdala. In addition, anxiety might be linked with the alterations in the microintegrity of UF, which suggested deficient connectivity of UF between orbitofrontal cortex, amygdala and temporal lobe. ${ }^{136-139}$

The limbic areas might connect with other brain region for the processing of fear response, which would be uncontrollable while panic attacks. ${ }^{6}$ The fear, arousal and attention toward threat would be modulated by the above fear-related regions. The experiences of panic attacks might also be linked with the emotional salience of the threat. ${ }^{8}$ The FOF might be important to input occipital and parietal-related sensory information and send frontal-related inhibitory control, which might be crucial for the pathophysiology of PD. The imaging genetics study showed that brain-derived neutrophic factor genotype would be associated with WM development of FOF, which was related to cognitive and intellectual function. ${ }^{140}$ The serotonin-related antidepressant would increase neurotrophic factor release in frontal regions, which might support the role of FOF in the WM pathophysiology of PD. In our study, we found antidepressant therapy increased the microintegri- 
ty of right UF and left FOF. In addition, the remitted patients with PD might compensate residual WM alterations of right UF through enhancing WM micro-structural integrity of left FOF. ${ }^{132,141}$ The antidepressant therapy might increase microintegrity through increasing neurotrophic factor release and relief of oxidative stress ${ }^{142}$ in right UF and left FOF. The antidepressant might influence the microstructure of WM tracts via the astrocyte-related factors, such as increasing glucose utilizations, expressions of astrocyte-derived neutrophic factors and lactate release, ${ }^{143}$ elevated cerebral blood flow and facilitating neurotransmission in neural circuits. ${ }^{144}$ The microintegrity of frontolimbic WM tracts was also associated with serotonin genotype polymorphism. ${ }^{145}$ The neurotrophic factor would have effects on brain fiber integrity. ${ }^{146}$ It also gives us a hint that antidepressant might increase serotonin release, which might modulate WM micro-structural integrity in the left FOF and right UF. These WM structural reports confirmed the role of occipital and temporal lobe in the advanced FNM.

\section{SUPPORTING EVIDENCES FROM CONNECTOME STUDY}

The functional connectome study of PD can also support the concept of advanced FNM. Recently our report showed that the alterations in the network including sensory and motor regions, which were connected with parahippocampus central hub. ${ }^{130}$ The alterations of parahippocamopus has been mentioned in PD, such as the elevated cerebral blood flow, reduced GM volume and increased benzodiazepine receptor bindings. ${ }^{19,30,147}$ Our VBM study found that PD comorbid with depression would parahippocampal GM reductions, ${ }^{20}$ which corresponded to the meta-analysis results. ${ }^{148}$ Two antidepressant studies in PD also demonstrated that antidepressant treatment would increase glucose metabolism in limbic regions, which also included the parahippocampus. ${ }^{149,150}$ Our results in left parahippocampus and its central hub role in functional connectome probably represented a large-scale neurophysiological alteration in PD. The altered connectivity between parahippocampus and dorsal cingulate cortex probably suggested the central role of limbic system. Our functional connectome results also corresponded to the lower activities ${ }^{151}$ and treatment response-related influences of neuronal stability in dorsal cingulate cortex ${ }^{152}$ of PD patients.

Our functional connectome study of PD also showed that the sensory regions, such as occipital lobe (calcarine gyrus and lingual gyrus) and parietal lobe (supramarginal gyrus, SMG), might be altered and influenced by the limbic system. ${ }^{130}$ The hyperperfusion of cerebral blood flow in parietal and temporal lobes have been reported in PD. ${ }^{45}$ In addition, the brain activities in parietal and temporal lobes were related to the psy- chopathology severity of $\mathrm{PD},{ }^{153}$ which were in line with our results of decreased connectivity strength between left parahippocampus gyrus and SMG. The PD patients had decreased activities in occipital lobe and other visual areas while exposing to the face task. ${ }^{154}$ The calcarine gyrus is an area of visuosensory function and the terminus of nervous impulses generated in the retina and the following visual response. ${ }^{155}$ The lower activities in the LING of PD patients were also discovered while face task..$^{156}$ The spatial scene memory and allocentric coding might be disturbed in $\mathrm{PD} .{ }^{157}$ The alterations within the limbic-sensory network might suggest that impaired control and feedback abilities, which be linked with the panic response while experiencing environmental stressors.

\section{CONCLUSION}

According to the above literature, we proposed the advanced

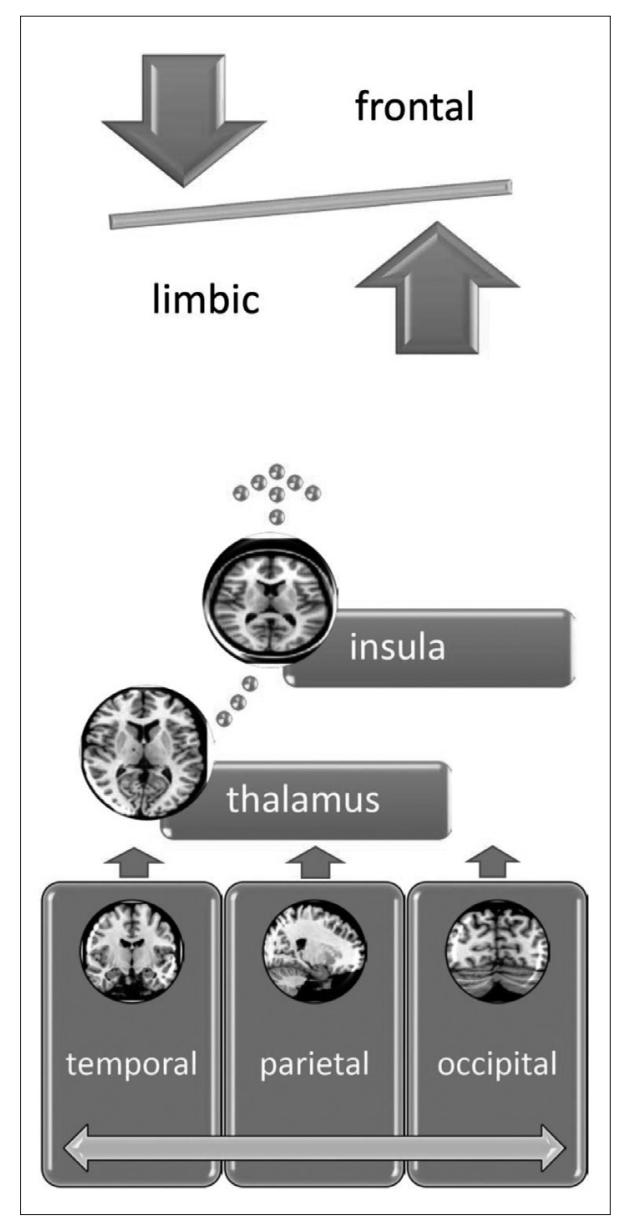

Figure 1. The advanced FNM for PD. The temporal, occipital and parietal lobes would input the sensory information to the thalamus for filtering the information. Then the filtered information would be integrated at the insula and then sent to the frontal regions for cognitive processing and limbic system for primitive response. The extended regions of FNM include the insula, thalamus, temporal, occipital and parietal lobes. FNM: fear network model, PD: panic disorder. 
FNM as an emerging model of fronto-limbic dysregulation with insula and sensory regions in the temporo-occipito-parietal lobe might be revealed according to the results of recent neuroimaging studies. The sensory regions, such as temporal, occipital and parietal lobes would input the sensory information to the thalamus for filtering the information. Then the filtered information would be integrated at the insula and then sent to the frontal regions for cognitive processing and limbic system for primitive response, which would be imbalanced in PD (Figure 1). The future delineation of advanced FNM model can be beneficial from more extensive and advanced studies focusing on imaging genetics, machine learning and pattern recognition to confirm the role of advanced FNM in the pathophysiology of PD.

\section{REFERENCES}

1. Wood WG. The diagnosis and management of panic disorder. Psychiatr Med 1990;8:197-209.

2. Culpepper L. Identifying and treating panic disorder in primary care. J Clin Psychiatry 2004;65(Suppl 5):19-23.

3. Weissman MM, Wickramaratne P, Adams PB, Lish JD, Horwath E, Charney $\mathrm{D}$, et al. The relationship between panic disorder and major depression. A new family study. Arch Gen Psychiatry 1993;50:767-780.

4. Rubin HC, Rapaport MH, Levine B, Gladsjo JK, Rabin A, Auerbach $\mathrm{M}$, et al. Quality of well being in panic disorder: the assessment of psychiatric and general disability. J Affect Disord 2000;57:217-221.

5. Barrera TL, Hiatt EL, Dunn NJ, Teng EJ. Impact of panic disorder on quality of life among veterans in a primary care pilot study. Compr Psychiatry 2013;54:256-261.

6. Gorman JM, Kent JM, Sullivan GM, Coplan JD. Neuroanatomical hypothesis of panic disorder, revised. Am J Psychiatry 2000;157:493505.

7. Pantazatos SP, Talati A, Pavlidis P, Hirsch J. Cortical functional connectivity decodes subconscious, task-irrelevant threat-related emotion processing. Neuroimage 2012;61:1355-1363.

8. Drabant EM, Ramel W, Edge MD, Hyde LW, Kuo JR, Goldin PR, et al. Neural mechanisms underlying 5-HTTLPR-related sensitivity to acute stress. Am J Psychiatry 2012;169:397-405.

9. Santos M, D’Amico D, Spadoni O, Amador-Arjona A, Stork O, Dierssen M. Hippocampal hyperexcitability underlies enhanced fear memories in TgNTRK3, a panic disorder mouse model. J Neurosci 2013; 33:15259-15271.

10. Sobanski T, Wagner G. Functional neuroanatomy in panic disorder: Status quo of the research. World J Psychiatry 2017;7:12-33.

11. Zwanzger P, Domschke K, Bradwejn J. Neuronal network of panic disorder: the role of the neuropeptide cholecystokinin. Depress Anxiety 2012;29:762-774.

12. Dresler T, Guhn A, Tupak SV, Ehlis AC, Herrmann MJ, Fallgatter AJ, et al. Revise the revised? New dimensions of the neuroanatomical hypothesis of panic disorder. J Neural Transm (Vienna) 2013;120:329.

13. Grambal A, Hlustik P, Prasko J. What fMRI can tell as about panic disorder: bridging the gap between neurobiology and psychotherapy. Neuro Endocrinol Lett 2015;36:214-225.

14. de Carvalho MR, Rozenthal M, Nardi AE. The fear circuitry in panic disorder and its modulation by cognitive-behaviour therapy interventions. World J Biol Psychiatry 2010;11:188-198.

15. Johnson LR, Hou M, Prager EM, Ledoux JE. Regulation of the fear network by mediators of stress: norepinephrine alters the Balance between cortical and subcortical afferent excitation of the lateral amyg- dala. Front Behav Neurosci 2011;5:23.

16. Asami T, Hayano F, Nakamura M, Yamasue $H$, Uehara $K$, Otsuka T, et al. Anterior cingulate cortex volume reduction in patients with panic disorder. Psychiatry Clin Neurosci 2008;62:322-330.

17. Asami T, Yamasue H, Hayano F, Nakamura M, Uehara K, Otsuka T, et al. Sexually dimorphic gray matter volume reduction in patients with panic disorder. Psychiatry Res 2009;173:128-134.

18. Hayano F, Nakamura M, Asami T, Uehara K, Yoshida T, Roppongi T, et al. Smaller amygdala is associated with anxiety in patients with panic disorder. Psychiatry Clin Neurosci 2009;63:266-276.

19. Massana G, Serra-Grabulosa JM, Salgado-Pineda P, Gasto C, Junque $\mathrm{C}$, Massana J, et al. Parahippocampal gray matter density in panic disorder: a voxel-based morphometric study. Am J Psychiatry 2003;160: 566-568.

20. Lai CH, Hsu YY, Wu YT. First episode drug-naive major depressive disorder with panic disorder: gray matter deficits in limbic and default network structures. Eur Neuropsychopharmacol 2010;20:676-682.

21. Sobanski T, Wagner G, Peikert G, Gruhn U, Schluttig K, Sauer H, et al. Temporal and right frontal lobe alterations in panic disorder: a quantitative volumetric and voxel-based morphometric MRI study. Psychol Med 2010;40:1879-1886.

22. Uchida RR, Del-Ben CM, Busatto GF, Duran FL, Guimaraes FS, Crippa JA, et al. Regional gray matter abnormalities in panic disorder: a voxel-based morphometry study. Psychiatry Res 2008;163:21-29.

23. Yoo HK, Kim MJ, Kim SJ, Sung YH, Sim ME, Lee YS, et al. Putaminal gray matter volume decrease in panic disorder: an optimized voxelbased morphometry study. Eur J Neurosci 2005;22:2089-2094.

24. Roppongi T, Nakamura M, Asami T, Hayano F, Otsuka T, Uehara K, et al. Posterior orbitofrontal sulcogyral pattern associated with orbitofrontal cortex volume reduction and anxiety trait in panic disorder. Psychiatry Clin Neurosci 2010;64:318-326.

25. Protopopescu X, Pan H, Tuescher O, Cloitre M, Goldstein M, Engelien A, et al. Increased brainstem volume in panic disorder: a voxel-based morphometric study. Neuroreport 2006;17:361-363.

26. van Tol MJ, van der Wee NJ, van den Heuvel OA, Nielen MM, Demenescu LR, Aleman A, et al. Regional brain volume in depression and anxiety disorders. Arch Gen Psychiatry 2010;67:1002-1011.

27. Lai CH, Wu YT. Fronto-temporo-insula gray matter alterations of firstepisode, drug-naive and very late-onset panic disorder patients. J Affect Disord 2012;140:285-291.

28. Lee YS, Hwang J, Kim SJ, Sung YH, Kim J, Sim ME, et al. Decreased blood flow of temporal regions of the brain in subjects with panic disorder. J Psychiatr Res 2006;40:528-534.

29. Nash JR, Sargent PA, Rabiner EA, Hood SD, Argyropoulos SV, Potokar JP, et al. Serotonin 5-HT1A receptor binding in people with panic disorder: positron emission tomography study. Br J Psychiatry 2008; 193:229-234.

30. Boshuisen ML, Ter Horst GJ, Paans AM, Reinders AA, den Boer JA. rCBF differences between panic disorder patients and control subjects during anticipatory anxiety and rest. Biol Psychiatry 2002;52: 126-135.

31. Gorman JM, Kent J, Martinez J, Browne S, Coplan J, Papp LA. Physiological changes during carbon dioxide inhalation in patients with panic disorder, major depression, and premenstrual dysphoric disorder: evidence for a central fear mechanism. Arch Gen Psychiatry 2001; 58:125-131.

32. Pillay SS, Gruber SA, Rogowska J, Simpson N, Yurgelun-Todd DA. fMRI of fearful facial affect recognition in panic disorder: the cingulate gyrus-amygdala connection. J Affect Disord 2006;94:173-181.

33. Windmann S. Panic disorder from a monistic perspective: integrating neurobiological and psychological approaches. J Anxiety Disord 1998; 12:485-507.

34. Kent JM, Coplan JD, Mawlawi O, Martinez JM, Browne ST, Slifstein $\mathrm{M}$, et al. Prediction of panic response to a respiratory stimulant by reduced orbitofrontal cerebral blood flow in panic disorder. Am J Psy- 
chiatry 2005;162:1379-1381.

35. Galderisi S, Mancuso F, Mucci A, Garramone S, Zamboli R, Maj M. Alexithymia and cognitive dysfunctions in patients with panic disorder. Psychother Psychosom 2008;77:182-188.

36. Hermans EJ, van Marle HJ, Ossewaarde L, Henckens MJ, Qin S, van Kesteren MT, et al. Stress-related noradrenergic activity prompts largescale neural network reconfiguration. Science 2011;334:1151-1153.

37. Spoormaker VI, Andrade KC, Schroter MS, Sturm A, Goya-Maldonado R, Samann PG, et al. The neural correlates of negative prediction error signaling in human fear conditioning. Neuroimage 2011;54:22502256.

38. Lai $\mathrm{CH}, \mathrm{Wu}$ YT. Changes in regional homogeneity of parieto-temporal regions in panic disorder patients who achieved remission with antidepressant treatment. J Affect Disord 2013;151:709-714.

39. Pourtois G, Thut G, Grave de Peralta R, Michel C, Vuilleumier P. Two electrophysiological stages of spatial orienting towards fearful faces: early temporo-parietal activation preceding gain control in extrastriate visual cortex. Neuroimage 2005;26:149-163.

40. Caseras X, Giampietro V, Lamas A, Brammer M, Vilarroya O, Carmona $\mathrm{S}$, et al. The functional neuroanatomy of blood-injection-injury phobia: a comparison with spider phobics and healthy controls. Psychol Med 2010;40:125-134.

41. Eser D, Leicht G, Lutz J, Wenninger S, Kirsch V, Schule C, et al. Functional neuroanatomy of CCK-4-induced panic attacks in healthy volunteers. Hum Brain Mapp 2009;30:511-522.

42. Leung MK, Chan CC, Yin J, Lee CF, So KF, Lee TM. Increased gray matter volume in the right angular and posterior parahippocampal gyri in loving-kindness meditators. Soc Cogn Affect Neurosci 2013; 8:34-39.

43. Liao W, Chen H, Feng Y, Mantini D, Gentili C, Pan Z, et al. Selective aberrant functional connectivity of resting state networks in social anxiety disorder. Neuroimage 2010;52:1549-1558.

44. Nagai M, Kishi K, Kato S. Insular cortex and neuropsychiatric disorders: a review of recent literature. Eur Psychiatry 2007;22:387-394.

45. Koh KB, Kang JI, Lee JD Lee YJ. Shared neural activity in panic disorder and undifferentiated somatoform disorder compared with healthy controls. J Clin Psychiatry 2010;71:1576-1581.

46. Lai $\mathrm{CH}, \mathrm{Wu}$ YT. The patterns of fractional amplitude of low-frequency fluctuations in depression patients: the dissociation between temporal regions and fronto-parietal regions. J Affect Disord 2015;175: 441-445.

47. Dresler T, Hahn T, Plichta MM, Ernst LH, Tupak SV, Ehlis AC, et al. Neural correlates of spontaneous panic attacks. J Neural Transm (Vienna) 2011;118:263-269.

48. Graeff FG, Del-Ben CM. Neurobiology of panic disorder: from animal models to brain neuroimaging. Neurosci Biobehav Rev 2008;32: 1326-1335.

49. Lai $\mathrm{CH}, \mathrm{Wu} \mathrm{YT}$. The gray matter alterations in major depressive disorder and panic disorder: putative differences in the pathogenesis. J Affect Disord 2015;186:1-6.

50. Damsa C, Kosel M, Moussally J. Current status of brain imaging in anxiety disorders. Curr Opin Psychiatry 2009;22:96-110.

51. Malizia AL. What do brain imaging studies tell us about anxiety disorders? J Psychopharmacol 1999;13:372-378.

52. Mobbs D, Marchant JL, Hassabis D, Seymour B, Tan G, Gray M, et al. From threat to fear: the neural organization of defensive fear systems in humans. J Neurosci 2009;29:12236-12243.

53. Cameron OG, Huang GC, Nichols T, Koeppe RA, Minoshima S, Rose $\mathrm{D}$, et al. Reduced gamma-aminobutyric acid(A)-benzodiazepine binding sites in insular cortex of individuals with panic disorder. Arch Gen Psychiatry 2007;64:793-800.

54. Feldker K, Heitmann CY, Neumeister P, Brinkmann L, Bruchmann $\mathrm{M}$, Zwitserlood P, et al. Cardiorespiratory concerns shape brain responses during automatic panic-related scene processing in patients with panic disorder. J Psychiatry Neurosci 2018;43:26-36.
55. Feldker K, Heitmann CY, Neumeister P, Bruchmann M, Vibrans L, Zwitserlood $\mathrm{P}$, et al. Brain responses to disorder-related visual threat in panic disorder. Hum Brain Mapp 2016;37:4439-4453.

56. Poletti S, Radaelli D, Cucchi M, Ricci L, Vai B, Smeraldi E, et al. Neural correlates of anxiety sensitivity in panic disorder: a functional magnetic resonance imaging study. Psychiatry Res 2015;233:95-101.

57. Fonzo GA, Ramsawh HJ, Flagan TM, Sullivan SG, Letamendi A, Simmons AN, et al. Common and disorder-specific neural responses to emotional faces in generalised anxiety, social anxiety and panic disorders. Br J Psychiatry 2015;206:206-215.

58. Wittmann A, Schlagenhauf F, Guhn A, Lueken U, Gaehlsdorf C, Stoy $\mathrm{M}$, et al. Anticipating agoraphobic situations: the neural correlates of panic disorder with agoraphobia. Psychol Med 2014;44:2385-2396.

59. Reinecke A, Thilo K, Filippini N, Croft A, Harmer CJ. Predicting rapid response to cognitive-behavioural treatment for panic disorder: the role of hippocampus, insula, and dorsolateral prefrontal cortex. Behav Res Ther 2014;62:120-128.

60. Magnotta VA, Johnson CP, Follmer R, Wemmie JA. Functional t1rho imaging in panic disorder. Biol Psychiatry 2014;75:884-891.

61. Gorka SM, Nelson BD, Phan KL, Shankman SA. Insula response to unpredictable and predictable aversiveness in individuals with panic disorder and comorbid depression. Biol Mood Anxiety Disord 2014; 4:9.

62. Pannekoek JN, van der Werff SJ, Stein DJ, van der Wee NJ. Advances in the neuroimaging of panic disorder. Hum Psychopharmacol 2013; 28:608-611.

63. Kim MK, Kim B, Kiu Choi T, Lee SH. White matter correlates of anxiety sensitivity in panic disorder. J Affect Disord 2017;207:148-156.

64. Choi JM, Padmala S, Pessoa L. Impact of state anxiety on the interaction between threat monitoring and cognition. Neuroimage 2012;59: 1912-1923.

65. Klucken T, Alexander N, Schweckendiek J, Merz CJ, Kagerer S, Osinsky $\mathrm{R}$, et al. Individual differences in neural correlates of fear conditioning as a function of 5-HTTLPR and stressful life events. Soc Cogn Affect Neurosci 2013;8:318-325.

66. Lai $\mathrm{CH}, \mathrm{Wu}$ YT. Patterns of fractional amplitude of low-frequency oscillations in occipito-striato-thalamic regions of first-episode drugnaive panic disorder. J Affect Disord 2012;142:180-185.

67. Pantazatos SP, Talati A, Pavlidis P, Hirsch J. Decoding unattended fearful faces with whole-brain correlations: an approach to identify condition-dependent large-scale functional connectivity. PLoS Comput Biol 2012;8:e1002441.

68. Meyer JH, Swinson R, Kennedy SH, Houle S, Brown GM. Increased left posterior parietal-temporal cortex activation after D-fenfluramine in women with panic disorder. Psychiatry Res 2000;98:133-143.

69. Qiu C, Liao W, Ding J, Feng Y, Zhu C, Nie X, et al. Regional homogeneity changes in social anxiety disorder: a resting-state fMRI study. Psychiatry Res 2011;194:47-53.

70. Eren I, Tukel R, Polat A, Karaman R, Unal S. Evaluation of regional cerebral blood flow changes in panic disorder with Tc99m-HMPAO SPECT. Psychiatry Res 2003;123:135-143.

71. Fredrikson M, Fischer H, Wik G. Cerebral blood flow during anxiety provocation. J Clin Psychiatry 1997;58(Suppl 16):16-21.

72. Osuch EA, Ketter TA, Kimbrell TA, George MS, Benson BE, Willis MW, et al. Regional cerebral metabolism associated with anxiety symptoms in affective disorder patients. Biol Psychiatry 2000;48:10201023.

73. Lai CH, Hsu YY. A subtle grey-matter increase in first-episode, drugnaive major depressive disorder with panic disorder after 6 weeks' duloxetine therapy. Int J Neuropsychopharmacol 2011;14:225-235.

74. Yoon HK, Kang J, Kwon DY, Ham BJ. Frontoparietal cortical thinning in respiratory-type panic disorder: a preliminary report. Psychiatry Investig 2016;13:146-151.

75. Yoon S, Jun CS, Jeong HS, Lee S, Lim SM, Ma J, et al. Altered cortical gyrification patterns in panic disorder: deficits and potential com- 
pensation. J Psychiatr Res 2013;47:1446-1454.

76. Nelson BD, Shankman SA. Visuospatial and mathematical dysfunction in major depressive disorder and/or panic disorder: a study of parietal functioning. Cogn Emot 2016;30:417-429.

77. Grambal A, Tudos Z, Hok P, Kamaradova D, Diveky T, Hlustik P, et al. Predictors of poor treatment response to additional CBT in real panic disorder patients: the role of DLPF, orbitofrontal cortex, parietal lobule, frontal eye field and amygdala in PD. Neuro Endocrinol Lett 2015;36:269-281.

78. Reif A, Richter J, Straube B, Hofler M, Lueken U, Gloster AT, et al. MAOA and mechanisms of panic disorder revisited: from bench to molecular psychotherapy. Mol Psychiatry 2014;19:122-128.

79. Lai $\mathrm{CH}, \mathrm{Wu} \mathrm{YT}$. The alterations in inter-hemispheric functional coordination of patients with panic disorder: the findings in the posterior sub-network of default mode network. J Affect Disord 2014;166: 279-284.

80. Heller W, Nitschke JB, Etienne MA, Miller GA. Patterns of regional brain activity differentiate types of anxiety. J Abnorm Psychol 1997; 106:376-385.

81. Lai $\mathrm{CH}, \mathrm{Wu}$ YT. Decreased regional homogeneity in lingual gyrus, increased regional homogeneity in cuneus and correlations with panic symptom severity of first-episode, medication-naive and late-onset panic disorder patients. Psychiatry Res 2013;211:127-131.

82. Katon W. Panic disorder: epidemiology, diagnosis, and treatment in primary care. J Clin Psychiatry 1986;47(Suppl):21-30.

83. Pannekoek JN, Veer IM, van Tol MJ, van der Werff SJ, Demenescu LR, Aleman A, et al. Aberrant limbic and salience network restingstate functional connectivity in panic disorder without comorbidity. J Affect Disord 2013;145:29-35.

84. Shin YW, Dzemidzic M, Jo HJ, Long Z, Medlock C, Dydak U, et al. Increased resting-state functional connectivity between the anterior cingulate cortex and the precuneus in panic disorder: resting-state connectivity in panic disorder. J Affect Disord 2013;150:1091-1095.

85. Pannekoek JN, Veer IM, van Tol MJ, van der Werff SJ, Demenescu LR, Aleman A, et al. Resting-state functional connectivity abnormalities in limbic and salience networks in social anxiety disorder without comorbidity. Eur Neuropsychopharmacol 2013;23:186-195.

86. Zhang S, Li CS. A neural measure of behavioral engagement: task-residual low-frequency blood oxygenation level-dependent activity in the precuneus. Neuroimage 2010;49:1911-1918.

87. Cavanna AE. The precuneus and consciousness. CNS Spectr 2007;12: 545-552.

88. Fletcher PC, Frith CD, Baker SC, Shallice T, Frackowiak RS, Dolan RJ. The mind's eye--precuneus activation in memory-related imagery. Neuroimage 1995;2:195-200.

89. Krause BJ, Schmidt D, Mottaghy FM, Taylor J, Halsband U, Herzog $\mathrm{H}$, et al. Episodic retrieval activates the precuneus irrespective of the imagery content of word pair associates. A PET study. Brain 1999;122 (Pt 2):255-263.

90. Klahn AL, Klinkenberg IA, Lueken U, Notzon S, Arolt V, Pantev C, et al. Commonalities and differences in the neural substrates of threat predictability in panic disorder and specific phobia. Neuroimage Clin 2017;14:530-537.

91. van de Riet WA, Grezes J, de Gelder B. Specific and common brain regions involved in the perception of faces and bodies and the representation of their emotional expressions. Soc Neurosci 2009;4:101-120.

92. Paquette V, Levesque J, Mensour B, Leroux JM, Beaudoin G, Bourgouin $\mathrm{P}$, et al. "Change the mind and you change the brain": effects of cognitive-behavioral therapy on the neural correlates of spider phobia. Neuroimage 2003;18:401-409.

93. Kumari V, ffytche DH, Das M, Wilson GD, Goswami S, Sharma T. Neuroticism and brain responses to anticipatory fear. Behav Neurosci 2007;121:643-652.

94. Japee S, Crocker L, Carver F, Pessoa L, Ungerleider LG. Individual differences in valence modulation of face-selective M170 response. Emo- tion 2009;9:59-69.

95. Bayle DJ, Taylor MJ. Attention inhibition of early cortical activation to fearful faces. Brain Res 2010;1313:113-123.

96. Hoehn-Saric R, Lee JS, McLeod DR, Wong DF. Effect of worry on regional cerebral blood flow in nonanxious subjects. Psychiatry Res 2005; 140:259-269.

97. Collignon O, Vandewalle G, Voss P, Albouy G, Charbonneau G, Lassonde $\mathrm{M}$, et al. Functional specialization for auditory-spatial processing in the occipital cortex of congenitally blind humans. Proc Natl Acad Sci U S A 2011;108:4435-4440.

98. Renier LA, Anurova I, De Volder AG, Carlson S, VanMeter J, Rauschecker JP. Preserved functional specialization for spatial processing in the middle occipital gyrus of the early blind. Neuron 2010;68:138148.

99. Urakawa T, Inui K, Yamashiro K, Tanaka E, Kakigi R. Cortical dynamics of visual change detection based on sensory memory. Neuroimage 2010;52:302-308

100. De Berardis D, Campanella D, Gambi F, La Rovere R, Sepede G, Core L, et al. Alexithymia, fear of bodily sensations, and somatosensory amplification in young outpatients with panic disorder. Psychosomatics 2007;48:239-246.

101. Liao W, Xu Q, Mantini D, Ding J, Machado-de-Sousa JP, Hallak JE, et al. Altered gray matter morphometry and resting-state functional and structural connectivity in social anxiety disorder. Brain Res 2011;1388: 167-177.

102. Mather M, Mitchell KJ, Raye CL, Novak DL, Greene EJ, Johnson MK. Emotional arousal can impair feature binding in working memory. J Cogn Neurosci 2006;18:614-625.

103. Ohrmann P, Pedersen A, Braun M, Bauer J, Kugel H, Kersting A, et al. Effect of gender on processing threat-related stimuli in patients with panic disorder: sex does matter. Depress Anxiety 2010;27:1034-1043.

104. Tauscher J, Bagby RM, Javanmard M, Christensen BK, Kasper S, Kapur S. Inverse relationship between serotonin 5-HT(1A) receptor binding and anxiety: a [(11)C]WAY-100635 PET investigation in healthy volunteers. Am J Psychiatry 2001;158:1326-1328.

105. Jackson PL, Meltzoff AN, Decety J. Neural circuits involved in imitation and perspective-taking. Neuroimage 2006;31:429-439.

106. Kitada R, Johnsrude IS, Kochiyama T, Lederman SJ. Brain networks involved in haptic and visual identification of facial expressions of emotion: an fMRI study. Neuroimage 2010;49:1677-1689.

107. Taylor SF, Liberzon I, Fig LM, Decker LR, Minoshima S, Koeppe RA. The effect of emotional content on visual recognition memory: a PET activation study. Neuroimage 1998;8:188-197.

108. Spoormaker VI, Sturm A, Andrade KC, Schroter MS, Goya-Maldonado R, Holsboer F, et al. The neural correlates and temporal sequence of the relationship between shock exposure, disturbed sleep and impaired consolidation of fear extinction. J Psychiatr Res 2010;44:11211128.

109. Carlson JM, Reinke KS, Habib R. A left amygdala mediated network for rapid orienting to masked fearful faces. Neuropsychologia 2009; 47:1386-1389

110. Gundel H, O'Connor MF, Littrell L, Fort C, Lane RD. Functional neuroanatomy of grief: an FMRI study. Am J Psychiatry 2003;160:19461953.

111. Maihofner C, Seifert F, Decol R. Activation of central sympathetic networks during innocuous and noxious somatosensory stimulation. Neuroimage 2011;55:216-224.

112. O'Connor MF, Gundel H, McRae K, Lane RD. Baseline vagal tone predicts BOLD response during elicitation of grief. Neuropsychopharmacology 2007;32:2184-2189.

113. Kret ME, Pichon S, Grezes J, de Gelder B. Similarities and differences in perceiving threat from dynamic faces and bodies. An fMRI study. Neuroimage 2011;54:1755-1762.

114. Leitman DI, Loughead J, Wolf DH, Ruparel K, Kohler CG, Elliott MA, et al. Abnormal superior temporal connectivity during fear percep- 
tion in schizophrenia. Schizophr Bull 2008;34:673-678.

115. Macey PM, Woo MA, Harper RM. Hyperoxic brain effects are normalized by addition of CO2. PLoS Med 2007;4:e173.

116. Premkumar P, Ettinger U, Inchley-Mort S, Sumich A, Williams SC, Kuipers E, et al. Neural processing of social rejection: the role of schizotypal personality traits. Hum Brain Mapp 2012;33:695-706.

117. Killgore WD, Yurgelun-Todd DA. Social anxiety predicts amygdala activation in adolescents viewing fearful faces. Neuroreport 2005;16: 1671-1675.

118. Nehlig A, Armspach JP, Namer IJ. SPECT assessment of brain activation induced by caffeine: no effect on areas involved in dependence. Dialogues Clin Neurosci 2010;12:255-263.

119. Schiltz C, Bodart JM, Dubois S, Dejardin S, Michel C, Roucoux A, et al. Neuronal mechanisms of perceptual learning: changes in human brain activity with training in orientation discrimination. Neuroimage 1999;9:46-62.

120. Kong J, Kaptchuk TJ, Webb JM, Kong JT, Sasaki Y, Polich GR, et al. Functional neuroanatomical investigation of vision-related acupuncture point specificity--a multisession fMRI study. Hum Brain Mapp 2009;30:38-46.

121. Kilts CD, Kelsey JE, Knight B, Ely TD, Bowman FD, Gross RE, et al. The neural correlates of social anxiety disorder and response to pharmacotherapy. Neuropsychopharmacology 2006;31:2243-2253.

122. Hahn B, Ross TJ, Stein EA. Neuroanatomical dissociation between bottom-up and top-down processes of visuospatial selective attention. Neuroimage 2006;32:842-853.

123. Breckel TP, Giessing C, Thiel CM. Impact of brain networks involved in vigilance on processing irrelevant visual motion. Neuroimage 2011; 55:1754-1762.

124. Tomasi D, Volkow ND. Association between functional connectivity hubs and brain networks. Cereb Cortex 2011;21:2003-2013.

125. Bremner JD, Vermetten E, Vythilingam M, Afzal N, Schmahl C, Elzinga B, et al. Neural correlates of the classic color and emotional stroop in women with abuse-related posttraumatic stress disorder. Biol Psychiatry 2004;55:612-620.

126. Goodwin RD, Fergusson DM, Horwood LJ. Childhood abuse and familial violence and the risk of panic attacks and panic disorder in young adulthood. Psychol Med 2005;35:881-890.

127. Mercado F, Carretie L, Hinojosa JA, Penacoba C. Two successive phases in the threat-related attentional response of anxious subjects: neural correlates. Depress Anxiety 2009;26:1141-1150.

128. Sander D, Grandjean D, Pourtois G, Schwartz S, Seghier ML, Scherer $\mathrm{KR}$, et al. Emotion and attention interactions in social cognition: brain regions involved in processing anger prosody. Neuroimage 2005;28: 848-858.

129. Seiferth NY, Pauly K, Habel U, Kellermann T, Shah NJ, Ruhrmann S, et al. Increased neural response related to neutral faces in individuals at risk for psychosis. Neuroimage 2008;40:289-297.

130. Lai $\mathrm{CH}, \mathrm{Wu} \mathrm{YT}$. The explorative analysis to revise fear network model for panic disorder: functional connectome statistics. Medicine (Baltimore) 2016;95:e3597.

131. Lai $\mathrm{CH}, \mathrm{Wu} \mathrm{YT}$. The changes in the low-frequency fluctuations of cingulate cortex and postcentral gyrus in the treatment of panic disorder: the MRI study. World J Biol Psychiatry 2016;17:58-65.

132. Lai $\mathrm{CH}, \mathrm{Wu}$ YT. Fronto-occipital fasciculus, corpus callosum and superior longitudinal fasciculus tract alterations of first-episode, medication-naive and late-onset panic disorder patients. J Affect Disord 2013;146:378-382.

133. Lai CH, Wu YT. The White Matter Microintegrity Alterations of Neocortical and Limbic Association Fibers in Major Depressive Disorder and Panic Disorder: The Comparison. Medicine (Baltimore) 2016;95: e2982.

134. Lai CH, Wu YT, Yu PL, Yuan W. Improvements in white matter microstructural integrity of right uncinate fasciculus and left fronto-occipital fasciculus of remitted first-episode medication-naive panic disor- der patients. J Affect Disord 2013;150:330-336

135. Tusa RJ, Ungerleider LG. The inferior longitudinal fasciculus: a reexamination in humans and monkeys. Ann Neurol 1985;18:583-591.

136. Baur V, Bruhl AB, Herwig U, Eberle T, Rufer M, Delsignore A, et al. Evidence of frontotemporal structural hypoconnectivity in social anxiety disorder: a quantitative fiber tractography study. Hum Brain Mapp 2013;34:437-446.

137. Hettema JM, Kettenmann B, Ahluwalia V, McCarthy C, Kates WR, Schmitt JE, et al. Pilot multimodal twin imaging study of generalized anxiety disorder. Depress Anxiety 2012;29:202-209.

138. Tromp do PM, Grupe DW, Oathes DJ, McFarlin DR, Hernandez PJ, Kral TR, et al. Reduced structural connectivity of a major frontolimbic pathway in generalized anxiety disorder. Arch Gen Psychiatry 2012; 69:925-934.

139. Zhang Y, Li L, Yu R, Liu J, Tang J, Tan L, et al. White matter integrity alterations in first episode, treatment-naive generalized anxiety disorder. J Affect Disord 2013;148:196-201.

140. Chiang MC, Barysheva M, Toga AW, Medland SE, Hansell NK, James $\mathrm{MR}$, et al. BDNF gene effects on brain circuitry replicated in 455 twins. Neuroimage 2011;55:448-454.

141. Lai CH, Wu YT, Yu PL, Yuan W. Improvements in white matter micro-structural integrity of right uncinate fasciculus and left fronto-occipital fasciculus of remitted first-episode medication-naive panic disorder patients. J Affect Disord 2013;150:330-336.

142. Lee CH, Park JH, Yoo KY, Choi JH, Hwang IK, Ryu PD, et al. Pre- and post-treatments with escitalopram protect against experimental ischemic neuronal damage via regulation of BDNF expression and oxidative stress. Exp Neurol 2011;229:450-459.

143. Allaman I, Fiumelli H, Magistretti PJ, Martin JL. Fluoxetine regulates the expression of neurotrophic/growth factors and glucose metabolism in astrocytes. Psychopharmacology (Berl) 2011;216:75-84.

144. Colloby SJ, Firbank MJ, He J, Thomas AJ, Vasudev A, Parry SW, et al. Regional cerebral blood flow in late-life depression: arterial spin labelling magnetic resonance study. Br J Psychiatry 2012;200:150-155.

145. Alexopoulos GS, Murphy CF, Gunning-Dixon FM, Glatt CE, Latoussakis V, Kelly RE Jr, et al. Serotonin transporter polymorphisms, microstructural white matter abnormalities and remission of geriatric depression. J Affect Disord 2009;119:132-141.

146. Chiang MC, Avedissian C, Barysheva M, Toga AW, McMahon KL, de Zubicaray GI, et al. Extending genetic linkage analysis to diffusion tensor images to map single gene effects on brain fiber architecture. Med Image Comput Comput Assist Interv 2009;12:506-513.

147. Hasler G, Nugent AC, Carlson PJ, Carson RE, Geraci M, Drevets WC. Altered cerebral gamma-aminobutyric acid type A-benzodiazepine receptor binding in panic disorder determined by [11C]flumazenil positron emission tomography. Arch Gen Psychiatry 2008;65:1166-1175.

148. Lai CH. Gray matter deficits in panic disorder: a pilot study of metaanalysis. J Clin Psychopharmacol 2011;31:287-293.

149. Sim HB, Kang EH, Yu BH. Changes in Cerebral Cortex and Limbic Brain Functions after Short-Term Paroxetine Treatment in Panic Disorder: An [F]FDG-PET Pilot Study. Psychiatry Investig 2010;7:215219.

150. Kang EH, Park JE, Lee KH, Cho YS, Kim JJ, Yu BH. Regional brain metabolism and treatment response in panic disorder patients: an [18F]FDG-PET study. Neuropsychobiology 2012;66:106-111.

151. Moon CM, Yang JC, Jeong GW. Explicit verbal memory impairments associated with brain functional deficits and morphological alterations in patients with generalized anxiety disorder. J Affect Disord 2015;186:328-336.

152. Lai CH, Wu YT. The changes in the low-frequency fluctuations of cingulate cortex and postcentral gyrus in the treatment of panic disorder: the MRI study. World J Biol Psychiatry 2016;17:58-65.

153. Wintermann GB, Donix M, Joraschky P, Gerber J, Petrowski K. Altered olfactory processing of stress-related body odors and artificial odors in patients with panic disorder. PLoS One 2013;8:e74655. 
154. Petrowski K, Wintermann G, Smolka MN, Huebner T, Donix M. The neural representation of emotionally neutral faces and places in patients with panic disorder with agoraphobia. J Affect Disord 2014;152154: 454-461.

155. Macmillan M. Alfred Walter Campbell and the visual functions of the occipital cortex. Cortex 2014;56:157-181.

156. Demenescu LR, Kortekaas R, Cremers HR, Renken RJ, van Tol MJ, van der Wee NJ, et al. Amygdala activation and its functional connectivity during perception of emotional faces in social phobia and panic disorder. J Psychiatr Res 2013;47:1024-1031.

157. Schmidt D, Krause BJ, Weiss PH, Fink GR, Shah NJ, Amorim MA, et al. Visuospatial working memory and changes of the point of view in 3D space. Neuroimage 2007;36:955-968. 